\title{
Investigation of the physical and psychosocial outcomes after living kidney donation - a multicenter cohort study (SoLKiD - Safety of Living Kidney Donors)
}

Barbara Suwelack $^{1 *}$ D, Viktoriya Wörmann ${ }^{2}$, Klaus Berger ${ }^{3}$, Joachim Gerß ${ }^{4}$, Heiner Wolters ${ }^{5}$, Frank Vitinius ${ }^{6}$, Markus Burgmer ${ }^{2}$ for the German SoLKiD consortium

\begin{abstract}
Background: Over the last years, living kidney donation (LKD) has been established for patients with endstage renal failure as an alternative to post mortem donation, which is limited by organ scarcity and long lasting waiting periods. From an ethical perspective, the increase in LKD requires that donors' physical, psychological, and social harm has to be minimized as much as possible and the risk should not exceed the generally expected consequences of nephrectomy. Despite of numerous, mainly retrospective studies about the postoperative outcome of LKD over the last years from different countries, it becomes apparent that there is a lack of comprehensive prospective multicenter research in this field worldwide. Therefore, the main aim of the study is to examine the physical and psychosocial outcome of living kidney donors in a prospective design before and after transplantation in an interdisciplinary approach (surgery, nephrology, psychosocial medicine).
\end{abstract}

Methods/design: The goal of the study is to investigate such aspects as the impact of gender-and age-specific factors on LKD outcome, donor outcome in correlation to the health status of the recipient, the medical and psychosocial risk of a healthy subject undergoing the LKD procedure. The study is carried out as a nationwide multicenter study. All adult living kidney donors with sufficient knowledge in the German, Russian, or Turkish language, informed consent, and place of residence in Germany are included. In a naturalistic design (cohort study), clinical data and self-report measures (questionnaires) of 320 donors are collected before and 8 weeks, 6 and 12 months after donation. Primary outcome parameters are the kidney function (estimated GFR) and the quality of life (SF-36) of the donor. Secondary outcome parameters are data about physical (e.g., wound healing, blood pressure) and psychosocial (fatigue, depression, anxiety, somatization) outcome after donation.

Discussion: Previous studies on the postoperative outcome of living kidney donors have methodological limitations and/or were carried out in countries with different healthcare systems, e.g. United States, Norway, Canada, United Kingdom. Thus, results cannot be generalized and are not particularly applicable to the risks of mainly caucasian living kidney donors in the German healthcare system. The study design overcomes these disadvantages in that it provides a prospective multicenter design.

Trial registration: German Clinical Trials Register DRKS00006552 (22 September 2014).

\footnotetext{
* Correspondence: Barbara.Suwelack@ukmuenster.de

'Department of Internal Medicine D, Transplant Nephrology, University

Hospital of Münster, Waldeyerstr.1, 48149 Münster, Germany

Full list of author information is available at the end of the article
} 


\section{Background}

For patients with endstage renal disease (ESRD), transplantation is currently the only treatment to regain an adequate renal function. Post mortem donation normally requires a long waiting time for the transplant recipient, due to the limited availability of organs. The actual waiting time in Germany is 6-7 years according to the German Organ Transplantation Foundation (Deutsche Stiftung Organtransplantation, https://www.dso.de/). Therefore, LKD has become an established alternative in recent years, which has many advantages for the kidney recipient. The transplantation can be done preemptively and is associated with a better rate of survival of the transplanted kidney as well as the organ recipient $[1,2]$. Quality of life (QoL) and life expectancy of the kidney recipient are improved and the occurrence of cardiovascular complications is reduced [3, 4]. Furthermore, a faster rehabilitation and a better reintegration into the daily activities and the occupational life contribute to reduce healthcare costs by $€ 280.000$ compared to continuing dialysis treatment [5]. Worldwide the percentage of LKDs among all kidney transplantations varies widely due to the scarcity of organs from post mortem donors (KDIGO Guideline Evidence Report) [6]. In Germany, approximately 30\% (living donors $n=645$ / post mortem $n=1550$ ) of all performed kidney transplantations were done with a living donor organ in 2015 (statistics.eurotransplant.org).

The German transplantation law requires that living donors should not be put at excessive risks due to the operation or its consequences. Relatively few published studies examined the surgical, general health, and psychosocial risks of donors following donation, most being retrospective in design. Older studies did not find an increased risk of advanced renal failure or of a relevant decline in glomerular filtration rate (GFR) in kidney donors compared to the general population [7-10]. In contrast, recent publications from registers in the US and in Norway reported a less favorable renal outcome among living kidney donors compared to a control group of potential donors from the healthy population $[11,12]$. The position paper of the European Committee on Organ Transplantation (CD-P-TO) criticized these studies because of their methodological limitations and listed a series of evidence, which contradict the results of both studies [13]. With relation to comorbidities, studies examining other outcomes, such as the impact of hypertension [14-16] or obesity [17] are scarce and also report conflicting results.

There are no prospective randomized multicenter studies on the psychosocial long-term risks and consequences for donors. Frade et al. examined QoL in donors before and after (18,8+/-12,8 months) donation and found only one significant improvement after donation of social functioning scores (from 79.1 to 89.8). The other SF-36 subscales remained unchanged [18]. Another study showed that living kidney donors after donation (on average 32 months) scored significantly better among the SF-36 scales "social functioning," "bodily pain," and "vitality" compared to the controls (healthy population) or to patients with renal tumors [19]. Some other studies, however, found that QoL was significantly reduced in the areas of physical [20-25] or mental health related $[26,27]$ components of QoL within the first post-operative period (up to 6 months). Most of these reductions were no longer found, however, at later measurement points. Some studies showed increased pain and fatigue within the first weeks after surgery and a higher incidence of mental disorders during the first 12 months postoperatively [20, 26, 28]. Important limitations of prior prospective studies included small sample sizes, monocentric conduction and the neglecting of the health status of the recipient as possibly influencing the donor's well-being. Further limitations include a lack of gender-specific aspects $[29,30]$ and the problem of limited transferability of results to other countries due to differences in the healthcare systems.

Aim of the SoLKiD study ("Safety of Living Kidney Donors") is to examine physical and psychosocial outcomes of living kidney donors based on a prospective multicenter design, an integration of relevant disciplines (surgery, urology, internal medicine, nephrology, psychosocial medicine), a detailed assessment of the psychosocial status at several time points, and additionally taking the recipient's health status into account.

\section{Methods/design}

\section{Study centers}

The study is carried out at 20 transplant centers in Germany. Participating centers are the University Hospitals of RWTH Aachen, Campus Charité Berlin Mitte, Campus Charité Berlin Virchow, Dresden, Düsseldorf, Essen, Frankfurt, Giessen, Hamburg-Eppendorf, Heidelberg, Halle (Saale), Schleswig-Holstein Campus Kiel, Schleswig-Holstein Campus Lübeck, Köln, Mainz, Mannheim, Münster, Würzburg, Westpfalz-Klinikum Campus Kaiserslautern, and Hannover Medical School. Donor-recipient pairs are recruited in the respective outpatient departments of the hospitals after signing informed consent. Study coordination is done at the University Hospital of Münster. The study is performed in accordance with the declaration of Helsinki and with the local ethics committees of all participating centers.

\section{Participants}

Inclusion and exclusion criteria for living kidney donors are listed in Table 1. 
Table 1 Inclusion and exclusion criteria of the SoLKiD study for living kidney donors

\begin{tabular}{ll}
\hline Inclusion criteria & $\cdot$ Living kidney donors before \\
& upcoming nephrectomy \\
$\cdot$ & Age $>17$ years \\
$\cdot$ & Informed consent \\
$\cdot$ & Native language German, Turkish, Russian \\
- Refusal to participate \\
$\cdot$ Not living in Germany \\
$\cdot$ Lack of reading comprehension in the \\
native language
\end{tabular}

As a common consensus between the participating centers, the Russian-speaking and Turkish-speaking donors are included in the study in addition to German-speaking donors, as they constitute a representative part of the population in Germany and because validated questionnaires in Turkish and Russian language are available. The study started in 2014 and included 320 donors for the baseline assessment prior to transplantation, corresponding to approximately $50 \%$ of the annually conducted living donations in Germany. With an expected follow-up rate of $>80 \%$, approximately 260 participants can be followed up to 1 year after donation.

\section{Measurement time points}

Living kidney donors and the associated organ recipients are examined at four time points (T0, T1, T2, T3) before donation and during the regular followup visits required by the transplant centers. All data for the baseline assessment (T0) is collected immediately (1-2 days) before the donation in order to avoid in the case of the earlier baseline assessment (e.g. during the preparation process for the donation) the possible donors' concern that they might be considered as not suitable for donation because of their answers. The data collection for all time points corresponds with the clinical routine process and is imbedded into the usual care practice of LKD. The time points of measurement of the study are shown in Fig. 1.

\section{Study measures: Primary and secondary outcome variables}

Data are collected by the transplant centers within the usual donor and recipient preparation and care. They include laboratory values (serum creatinine, eGFR, proteinuria, blood sugar levels), and clinical data (blood pressure, weight, surgical complications). In addition, further information, in particular psychosocial status variables, are collected by means of questionnaires at four time points. Questionnaires used in the study are listed in Table 2.

Estimated GFR (eGFR) using the CKD-EPI creatinine equation [31] of the donor and the physical and mental summary scores of the SF-36 are defined as primary outcome variables. All other outcomes of the physical and mental health status of the donor are used as secondary outcomes.

Psychosocial consequences for a donor can either be assessed as a reduction in the mental health score of the SF-36, or as an increase in depression or anxiety scores, or as an increase in scores for somatization (PHQ-D), change in psychosocial functioning and increased stress (PSS-10) or fatigue (MFI). Additionally, at baseline different components of a habitual cognitive emotion regulation scale (CERQ) are assessed, enabling a control of the relationship between the present ability of adequate emotion regulation and postoperative psychosocial consequences in donors.

Psychosocial variables which reflect the current mental state of donors additionally include the subjective attitude towards donation and the assessment of donor-specific relationship aspects to the recipient. This includes, for example, if a donor would donate again, or if he/she felt him/herself to be pushed towards donation by others. All questionnaires are offered either in German, Russian or Turkish validated versions. Information is collected independently from donor and from recipient to avoid a two-way influence during the assessment. The standardized assessment form with the clinical data of donors and recipients plus the donor questionnaires are sent in a pseudonymized manner to the data management center in Münster at all four time points.

Fig. 1 Time points of measurement in the SoLKiD study




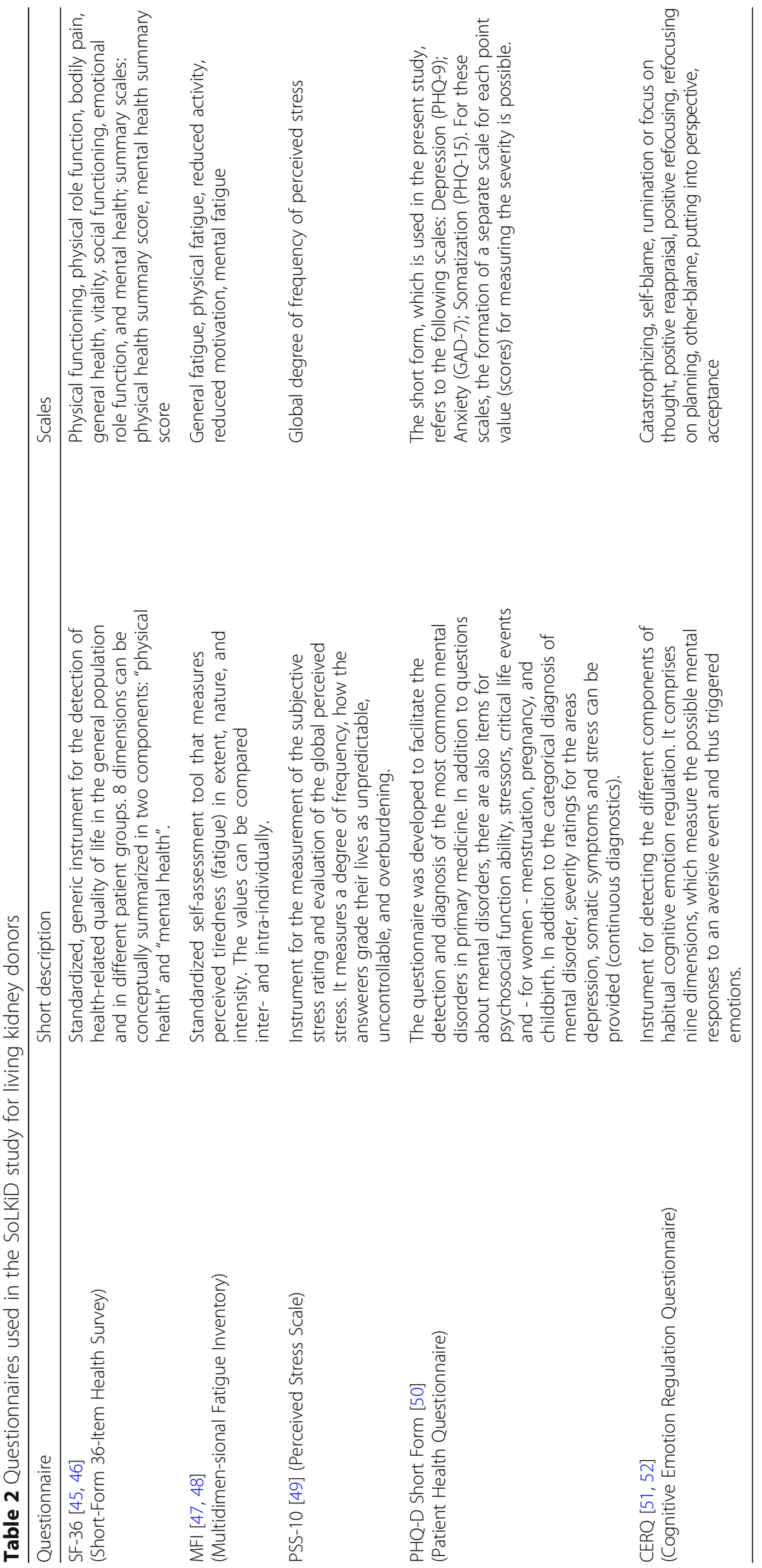




\section{Statistical analysis}

Statistical analyses will be performed according to the principles of the ICH-guideline E9 "Statistical Principles for Clinical Trials" using standard statistical software.

A detailed description of the study population will be given using summary statistics such as mean and standard deviation, median and quartiles, or absolute and relative frequencies, as appropriate.

Each of the three co-primary outcomes, i.e. the donors' eGFR and QoL according to the SF-36 "physical health" and "mental health" summary score will be analyzed using a Mixed Linear Model. This method is chosen in order to account for repeated measurements of individual donors' outcomes over time (longitudinal data). One important advantage of the Mixed Model approach is that missing values in outcomes are handled in a way that prevents biased results. In the established models, all relevant independent variables will be included that impact the respective outcome, first of all the baseline values of the respective outcomes. Furthermore prognostic factors as gender, age, and education will be included in the model in order to adjust for confounding. Basic model assumptions such as the Gaussian distribution of model residuals will be checked using graphical methods, including histograms and quantile-quantile plots. If necessary, outcome variables will be transformed appropriately, applying square-root, logarithmic or Box-Cox transformations. Models will be fitted using Restricted Maximum Likelihood methods. Model selection will be performed using stepwise variable selection methods based on Akaike's information criterion. Final models will be validated by diagnostic checks including the calculation of goodness of fit statistics and the examination of the randomness of model residuals. The model's predictive performance will be checked using cross-validation.

In the primary statistical analysis, the following hypothesis test problems are established in an analogous manner in case of each of the three co-primary outcomes eGFR, SF-36 "physical health" and "mental health" summary score. Denote $\mu_{\mathrm{i}}(i=1,2,3)$ the expected values of the respective outcome at three consecutive follow-up visits T1, T2, and T3. The global null hypothesis $\mathrm{H}_{0}: \mu_{1}=\mu_{2}=\mu_{3}$ is established and tested against the alternative $\mathrm{H}_{1}: \exists(\mathrm{i}, \mathrm{j}) \in\{1,2,3\}: \mu_{\mathrm{i}} \neq \mu_{\mathrm{j}}$ in order to detect any kind of mean changes over time. Beyond the global null hypothesis, pairwise comparisons of expected values $\mu_{\mathrm{i}}(\mathrm{i}=1,2,3)$ are performed by testing the null hypotheses $\mathrm{H}_{0}^{(12)}: \mu_{1}=\mu_{2}, \mathrm{H}_{0}^{(13)}: \mu_{1}=\mu_{3}$ und $\mathrm{H}_{0}^{(23)}: \mu_{2}=\mu_{3}$ against the corresponding two-sided alternatives. The overall multiple significance level across the three coprimary outcomes is set to $\alpha=0.05$. In order to keep this significance level, Bonferroni adjustment is applied. Each of the three co-primary outcomes is assigned the local significance level $\alpha_{\text {loc }}=0.05 / 3=0.0167$, i.e., $\alpha_{\text {loc }}^{\text {eGFR }}=$ $0.0167, \alpha_{\text {loc }}^{\text {SF36phys }}=0.0167$ and $\alpha_{\text {loc }}^{\text {SF36mental }}=0.0167$. Within each of the three co-primary outcomes, the following multiple testing strategy is applied, that is derived from the closed test principle. Denote the calculated $p$-values of the pairwise null hypotheses $\mathrm{H}_{0}^{(i \mathrm{i})}: \mu_{\mathrm{i}}=\mu_{\mathrm{j}}$ $(\mathrm{i}, \mathrm{j} \in\{1,2,3\}) \mathrm{p}_{\mathrm{ij}}$ and the $\mathrm{p}$-value of the global null hypothesis $\mathrm{H}_{0}: \mu_{1}=\mu_{2}=\mu_{3} \mathrm{p}_{123}$. Any specific pairwise null hypothesis $\mathrm{H}_{0}^{(\mathrm{ij})}$ is rejected if and only if both $\mathrm{p}_{\mathrm{ij}} \leq 0.0167$ and $\mathrm{p}_{123} \leq 0.0167$. This multiple testing strategy provides strong control of the family-wise type I error rate $\alpha_{\mathrm{loc}}=0.0167$. Each of the above null hypotheses will be tested using Wald type tests of the respective contrasts in the final established Mixed Linear Model. Point estimators of all contrasts will be supplemented by (two-sided) confidence intervals. The primary efficacy analysis provides confirmatory statistical evidence. Secondary outcomes will be analyzed using descriptive and inferential statistical methods. Appropriate tests will be applied for prespecified hypotheses. Point estimates and associated 95\% confidence intervals will be provided.

Further exploratory and safety analyses will be performed. In exploratory and safety analyses, no correction for multiplicity will be applied. An overall or multiple significance level is not determined and cannot be calculated. Results are regarded noticeable in case $p \leq 0.05$, and are interpreted, accounting for the relatively low level of scientific evidence.

\section{Sample size calculation}

The necessary number of study participants follows from the anticipated effects in the three co-primary outcomes. In Gossmann et al. [7], the observed mean eGFR was $92 \mathrm{~mL} / \mathrm{min} / 1.73 \mathrm{~m}^{2}$ before and $71 \mathrm{~mL} / \mathrm{min} /$ $1.73 \mathrm{~m}^{2}$ after donation (relative difference $|\Delta \mathrm{rel}| \approx$ $23 \%$ ), each with a standard deviation of $15-20 \mathrm{~mL} /$ $\min / 1.73 \mathrm{~m}^{2}$. Similar results were obtained in the study by Ibrahim et al. [9]. In Kroencke et al. [21], average SF-36 "physical health" summary scores were observed at successive measurement time points, that vary between 51 and 56 units $(\mid \Delta$ rel $\mid \approx 10 \%)$, each with a standard deviation of up to 8 units. The SF-36 "mental health" summary score amounted to around 53 units and relatively stable in time, with standard deviations of $6.3,8.9$ and 7.7 units at the three consecutive measurement time points. Similar results were obtained in the retrospective study of Wiedebusch et al. [32], who reported SF-36 summary scores of 51-52 units with a standard deviation of 9 units 6 months after surgery. In case of all outcomes, measures obtained from an individual study 
participant at successive measurement time points are assumed to be positively correlated. A total number of 320 pairs of kidney donors and recipients will be included in the study, resulting in $2 \times 320=640$ study participants. A number of 200 pairs of kidney donors and recipients is expected to provide evaluable data. With this sample size, the above reported differences in the co-primary outcomes eGFR and SF-36 "physical health" summary score can be detected with a power of $>90 \%$ in the primary statistical analysis. For the third co-primary outcome SF-36 "mental health" summary score, possible mean differences between successive measurement time points in the order of 3 units $(|\Delta \mathrm{rel}| \approx 6 \%)$ can be detected with a power of $>85 \%$. Power calculations were performed using the SAS software.

\section{Discussion}

The aim of the SoLKiD study is to investigate the physical and psychosocial outcomes of living kidney donors during a 12-months course after donor nephrectomy in a prospective multicenter design. It aims to answer the question, which health risks might arise from the elective removal of one kidney from a healthy donor. The interdisciplinary approach enables the assessment of a broad number of physical and psychosocial health status outcomes in order to provide a comprehensive overview of the consequences and the natural course after LKD. Studies on the physical consequences of LKD show divergent results. They reported, on the one hand, an agedependent decrease of the eGFR of up to $30 \%$ within 10 years after donation especially in female donors [710]. On the other hand, they did not find a higher rate of renal insufficiency, compared to the general population [9]. However, these studies were mostly based on young and healthy donors. Register studies in the US and Norway showed reduced life expectancy and higher rates of ESRD than in the healthy population basically able to donate [11, 12]. Regarding arterial hypertension as the most important risk factor in the general population for cardiovascular morbidity and mortality, about $15 \%$ of donors develop it after kidney donation (in Germany up to $10 \%)[14,33]$. Data from the Norwegian health registers showed a prevalence of hypertension 5 years after donation of about 27\% [15]. In contrast, another study did not find an increased prevalence of hypertension in donors compared to their nonnephrectomized twins [16]. Such differing results could be explained by varying observation times, in the study by Mjoen et al. 5 years after LKD, in the study by Najarian et al. 20 years after LKD $[15,16]$. Some studies found an increased cardiovascular mortality especially in the subgroup of older donors with declining eGFR [34, 35]. Generally speaking, findings about the increased mortality in living kidney donors reported above cannot be maintained because of their methodological limitations, such as age difference between donors and controls, lack of matching of age [36], or selected donor population (donors and recipients with immunemediated kidney disease are biologically related or African Americans) [13]. Furthermore, a matched cohort study of Reese et al. with a sample of 5152 donors aged $>55$ years old showed that there are no differences regarding mortality between older kidney donors and healthy participants [37]. Whether a donor with preexisting and treated hypertension can be accepted for donation must be considered carefully. One single center study with a low number of older and obese donors demonstrated worse renal function compared to nonobese donors [38]. Especially older donors seem to have an increased obesity-associated risk for hypertension, which cannot be attributed to nephrectomy alone [39, 40]. There are also no data regarding gender-specific consequences of donation. In the US, a trend already indicates that donors are increasingly older, medically complex ill, overweight, and often hypertensive or even have pre-diabetes $[39,41]$. Thus, more donors with socalled "isolated medical abnormalities" are accepted.

Studies on the QoL of donors after LKD found similar or slightly higher scores compared to the general population $[18,19,42]$. High QoL is associated with a positive attitude towards the provided donation $[9,29,32,42-44]$, but little is known about risk factors for adverse psychosocial outcomes. Because previous studies were mostly conducted retrospectively, a large variation in the follow-up time after donation (up to 48 years) exists, introducing a potential for recall bias. Many studies were cross-sectional in design allowing no conclusion on the change in QoL after donation. Thus, because of methodological limitations in several prior studies, their results cannot be generalized. The SoLKiD study with its prospective, multicenter design will add to the outcome data of living kidney donors. In view of an ongoing controversial debate about transplantation medicine in Germany, which is likely to further reduce the post mortem organ availability, and also because of the debate on the allowable scope of living donation, the SoLKiD results can provide a valuable database for transplant professionals to facilitate the discussion about potential risks, as well as for patients and their families to help them reach an informed decision about the donation.

\section{Acknowledgements}

We are grateful to all participating centers in assessing the data. Many thanks go to the study nurses of each participating center for their help with the data collection. Finally, we are especially indebted to all donors and recipients who participated in this study. 


\section{SoLKiD consortium}

The SoLKiD consortium is constituted of Anja S Mühlfeld, Fabian Halleck, Klemens Budde, Petra Reinke, Anett Sefrin, Roger Wahba, Christian Hugo, Mirian Opgenoorth, Magdalena Woznowski, Anita Hansen, Andreas Kribben, Oliver Witzke, Steffen Platschek, Ingeborg A Hauser, Rolf Weimer, Lucy Rainer, Karl Weigand, Gerit Theil, Sylvia Kroencke, Martina Koch, Mario Schiffer, Frank Lehner, Martin Zeier, Claudia Sommerer, Thomas Rath, Georgios Papadopoulos, Thorsten Feldkamp, Astrid Fülbier, Martin Nitschke, Jessika Schlieter, Beate Schamberger, Jens Lutz, Kai Nowak, Bernd Krüger, Manuela Kirchner and Kai Lopau.

\section{Funding}

After external two step peer-review the study was funded by the Federal German Ministry of Education and Research (BMBF) Health Research (code: 01 GY1321).

\section{Availability of data and materials}

Not applicable.

\section{Authors' contributions}

BS is the corresponding author and one of the Principal investigators of the SoLKiD consortium. She initiated and contributed to the planning, organizing and performing of the study and was a major contributor in writing of the manuscript and WW contributed equally to the organizing and performing of the study and was the major contributor in writing the manuscript. KB is one of the Principal investigators of the SoLKiD consortium. He contributed to the planning, organizing and performing of the study, is the head of the principal data coordination department and was a major contributor in writing of the manuscript. JG is one of the Principal investigators of the SoLKiD consortium. He contributed to the planning, organizing and performing of the study, is a major contributor to data analysis and writing of the manuscript. HW is one of the Principal investigators of the SoLKiD consortium. He contributed to the planning, organizing and performing of the study and was a major contributor in writing of the manuscript. FV is a major contributor in writing the manuscript. He contributed to the organizing and performing of the study. $\mathrm{MB}$ is one of the Principal investigators and the spokesman of the SoLKiD consortium. He initiated and contributed to the planning, organizing and performing of the study and was a major contributor in writing of the manuscript. All authors read and approved the final manuscript.

\section{Ethics approval and consent to participate}

The study is approved by the local ethics committees of all participating centers who affiliated to the vote of the principal ethics committee of the Westfalian Wilhelms University of Münster WWU (code-2013-587-f-S).

\section{Consent for publication}

Not applicable.

\section{Competing interests}

The authors declare that they have no competing interests.

\section{Publisher's Note}

Springer Nature remains neutral with regard to jurisdictional claims in published maps and institutional affiliations.

\section{Author details}

${ }^{1}$ Department of Internal Medicine D, Transplant Nephrology, University Hospital of Münster, Waldeyerstr.1, 48149 Münster, Germany. ${ }^{2}$ Department of Psychosomatics and Psychotherapy, University Hospital of Münster, Domagkstr. 22, 48149 Münster, Germany. ${ }^{3}$ Institute of Epidemiology and Social Medicine, University of Münster, Domagkstr. 3, 48129 Muenster Germany. ${ }^{4}$ Institute of Biostatistics and Clinical Research, University of Münster, Schmeddingstr. 56, 48149 Münster, Germany. ${ }^{5}$ Department of General and Visceral Surgery, University Hospital of Münster, Albert-Schweitzer-Campus 1, 48149 Muenster, Germany. ${ }^{6}$ Department of Psychosomatics and Psychotherapy, University Hospital of Cologne, Kerpener Str. 62, 50937 Cologne, Germany.
Received: 23 April 2017 Accepted: 13 March 2018

Published online: 10 April 2018

\section{References}

1. Hariharan S, Johnson CP, Bresnahan BA, Taranto SE, Mclntosh MJ, Stablein D. Improved graft survival after renal transplantation in the United States, 1988 to 1996. N Engl J Med. 2000;342:605-12.

2. Meier-Kriesche HU, Port FK, Ojo AO, Rudich SM, Hanson JA, Cibrik DM, Leichtman AB, Kaplan B. Effect of waiting time on renal transplant outcome. Kidney Int. 2000;58:1311-7.

3. Perl J, Zhang J, Gillespie B, Wikstrom B, Fort J, Hasegawa T, Fuller DS, Pisoni RL, Robinson BM, Tentori F. Reduced survival and quality of life following return to dialysis after transplant failure: the Dialysis outcomes and practice patterns study. Nephrol Dial Transplant. 2012;27:4464-72.

4. Port FK, Wolfe RA, Mauger EA, Berling DP, Jiang K. Comparison of survival probabilities for dialysis patients vs cadaveric renal transplant recipients. JAMA. 1993;270:1339-43.

5. Heemann U, Renders L. State of living kidney donation in Europe. Nephrol Dial Transplant. 2012;27:2166-70.

6. Brasure, M, Slinin Y, Carlyle M, Ishani A, Eidman K, Bydash J, Maripuri S, Wilt TJ: Outcomes of living kidney donation: a systematic review for a clinical practice guideline by the kidney disease improving global outcomes (KDIGO). November 2015, http://kdigo.org/home/guidelines/livingdonor/

7. Gossmann J, Wilhelm A, Kachel HG, Jordan J, Sann U, Geiger H, Kramer W, Scheuermann EH. Long-term consequences of live kidney donation followup in $93 \%$ of living kidney donors in a single transplant center. Am 」 Transplant. 2005;5:2417-24.

8. Hoerger TJ, Wittenborn JS, Segel JE, Burrows NR, Imai K, Eggers P, Pavkov ME, Jordan R, Hailpern SM, Schoolwerth AC, Williams DE. A health policy model of CKD: 1. Model construction, assumptions, and validation of health consequences. Am J Kidney Dis. 2010;55:452-62.

9. Ibrahim HN, Foley R, Tan L, Rogers T, Bailey RF, Guo H, Gross CR, Matas AJ. Long-term consequences of kidney donation. N Engl J Med. 2009; 360:459-69

10. Poggio ED, Braun WE, Davis C. The science of stewardship: due diligence for kidney donors and kidney function in living kidney donation-evaluation, determinants, and implications for outcomes. Clin J Am Soc Nephrol. 2009: 4:1677-84.

11. Muzaale AD, Massie AB, Wang MC, Montgomery RA, McBride MA, Wainright $J$, Segev DL. Risk of end-stage renal disease following live kidney donation. JAMA. 2014;311:579-86.

12. Mjøen G, Hallan S, Hartmann A, Foss A, Midtvedt K, Øyen O, Reisæter A, Pfeffer P, Jenssen T, Leivestad T, Line PD, Øvrehus M, Dale DO, Pihlstrøm H, Holme I, Dekker FW, Holdaas H. Long-term risks for kidney donors. Kidney Int. 2014;86:162-7.

13. Biancone L, Cozzi E, Lopez-Fraga M, Nanni-Costa A. Long-term outcome of living kidney donation. Position paper of the European committee on organ transplantation (CD-P-TO), Council of Europe. Transpl Int. 2016;29:129-31.

14. Tent H, Sanders JS, Rook M, Hofker HS, Ploeg RJ, Navis G, van der Heide JJ. Effects of preexistent hypertension on blood pressure and residual renal function after donor nephrectomy. Transplantation. 2012;93:412-7.

15. Mjoen G, Midtvedt K, Holme I, Oyen O, Fauchald P, Bergrem H, Holdaas H. One- and five-year follow-ups on blood pressure and renal function in kidney donors. Transpl Int. 2011;24:73-7.

16. Najarian JS, Chavers BM, McHugh LE, Matas AJ. 20 years or more of followup of living kidney donors. Lancet. 1992;340:807-10.

17. Segev DL, Muzaale AD, Caffo BS, Mehta SH, Singer AL, Taranto SE, McBride MA, Montgomery RA. Perioperative mortality and long-term survival following live kidney donation. JAMA. 2010;303:959-66.

18. Frade IC, Fonseca I, Dias L, Henriques AC, Martins LS, Santos J, Sarmento M, Lopes A. Impact assessment in living kidney donation: psychosocial aspects in the donor. Transplant Proc. 2008:40:677-81.

19. Maglakelidze N, Pantsulaia T, Managadze L, Chkhotua A. Assessment of healthrelated quality of life in living kidney donors. Transplant Proc. 2011;43:373-5.

20. Bergman S, Feldman LS, Mayo NE, Carli F, Anidjar M, Klassen DR, Andrew CG, Vassiliou MC, Stanbridge DD, Fried GM. Measuring surgical recovery: the study of laparoscopic live donor nephrectomy. Am J Transplant. 2005;5: 2489-95.

21. Kroencke S, Fischer L, Nashan B, Herich L, Schulz KH. A prospective study on living related kidney donors' quality of life in the first year: choosing appropriate reference data. Clin Transpl. 2012;26:E418-27. 
22. Lumsdaine JA, Wray A, Power MJ, Jamieson NV, Akyol M, Andrew BJ, Forsythe $J$, Wigmore SJ. Higher quality of life in living donor kidney transplantation: prospective cohort study. Transpl Int. 2005;18:975-80.

23. Smith GC, Trauer T, Kerr PG, Chadban SJ. Prospective psychosocial monitoring of living kidney donors using the SF-36 health survey. Transplantation. 2003;76:807-9.

24. Virzi A, Signorelli MS, Veroux M, Giammarresi G, Maugeri S, Nicoletti A, Veroux P. Depression and quality of life in living related renal transplantation. Transplant Proc. 2007;39:1791-3.

25. Walton-Moss B, Boulware LE, Cooper M, Taylor L, Dane K, Nolan MT. Prospective pilot study of living kidney donor decision-making and outcomes. Clin Transpl. 2007;21:86-93.

26. Smith GC, Trauer T, Kerr PG, Chadban SJ. Prospective psychosocial monitoring of living kidney donors using the short Form-36 health survey: results at 12 months. Transplantation. 2004;78:1384-9.

27. Erim $Y$, Kahraman $Y$, Vitinius F, Beckmann M, Kröncke S, Witzke O. Resilience and quality of life in 161 living kidney donors before nephrectomy and in the aftermath of donation: a naturalistic single center study. BMC Nephrol. 2015;16:164. https://doi.org/10.1186/s12882-015-0160-z

28. de Groot IB, Stiggelbout AM, van der Boog PJ, Baranski AG, Marang-van de Mheen PJ. Reduced quality of life in living kidney donors: association with fatigue, societal participation and pre-donation variables. Transpl Int. 2012; 25:967-75.

29. Mjoen G, Stavem K, Westlie L, Midtvedt K, Fauchald P, Norby G, Holdaas H. Quality of life in kidney donors. Am J Transplant. 2011;11:1315-9.

30. Westlie L, Fauchald P, Talseth T, Jakobsen A, Flatmark A. Quality of life in Norwegian kidney donors. Nephrol Dial Transplant. 1993;8:1146-50.

31. Levey AS, Stevens LA, Schmid CH, Zhang YL, Castro AF, Feldman HI, Kusek JW, Eggers P, van Lente F, Greene T, Coresh J. A new equation to estimate glomerular filtration rate. Ann Intern Med. 2009;150:604-12.

32. Wiedebusch S, Reiermann S, Steinke C, Muthny FA, Pavenstaedt HJ, SchoeneSeifert B, Senninger N, Suwelack B, Buyx AM. Quality of life, coping, and mental health status after living kidney donation. Transplant Proc. 2009;41:1483-8.

33. Beschreibung der Qualitätsindikatoren für das Erfassungsjahr 2015. Nierenlebendspende. IQTIG - Institut für Qualitätssicherung und Transparenz im Gesundheitswesen, 04.05.2016. https://www.iqtig.org

34. Garg AX, Meirambayeva A, Huang A, Kim J, Prasad GV, Knoll G, Boudville N, Lok C, McFarlane P, Karpinski M, Storsley L, Klarenbach S, Lam N, Thomas SM, Dipchand C, Reese P, Doshi M, Gibney E, Taub K, Young A. Cardiovascular disease in kidney donors: matched cohort study. BMJ. 2012; 344:e1203. https://doi.org/10.1136/bmj.e1203.

35. Mjoen G, Reisaeter A, Hallan S, Line PD, Hartmann A, Midtvedt K, Foss A, Dahle DO, Holdaas H. Overall and cardiovascular mortality in Norwegian kidney donors compared to the background population. Nephrol Dial Transplant. 2012;27:443-7.

36. Kaplan B, llahe A. Quantifying risk of kidney donation: the truth is not out there (yet). Am J Transplant. 2014;14:1715-6.

37. Reese PP, Bloom RD, Feldman HI, Rosenbaum P, Wang W, Saynisch P, Tarsi NM, Mukherjee N, Garg AX, Mussell A, Shults J, Even-Shoshan O, Townsend RR, Silber JH. Mortality and cardiovascular disease among older live kidney donors. Am J Transplant. 2014;14:1853-61.

38. O'Brien B, Mastoridis S, Sabharwal A, Hakim N, Taube D, Papalois V. Expanding the donor pool: living donor nephrectomy in the elderly and the overweight. Transplantation. 2012;93:1158-65.

39. Taler SJ, Messersmith EE, Leichtman AB, Gillespie BW, Kew CE, Stegall MD, Merion RM, Matas AJ, Ibrahim HN. Demographic, metabolic, and blood pressure characteristics of living kidney donors spanning five decades. Am J Transplant. 2013;13:390-8.

40. Tan JC, Chertow GM. Cautious optimism concerning long-term safety of kidney donation. N Engl J Med. 2009;360:522-3.

41. Cherikh WS, Young CJ, Kramer BF, Taranto SE, Randall HB, Fan PY. Ethnic and gender related differences in the risk of end-stage renal disease after living kidney donation. Am J Transplant. 2011;11:1650-5.

42. Clemens KK, Thiessen-Philbrook H, Parikh CR, Yang RC, Karley ML, Boudville N, Ramesh Prasad GV, Garg AX. Psychosocial health of living kidney donors: a systematic review. Am J Transplant. 2006;6:2965-77.

43. Giessing M, Reuter S, Schonberger B, Deger S, Tuerk I, Hirte I, Budde K, Fritsche L, Morgera S, Neumayer HH, Loening SA. Quality of life of living kidney donors in Germany: a survey with the validated short Form-36 and Giessen subjective complaints List-24 questionnaires. Transplantation. 2004; 78:864-72.
44. Reimer J, Rensing A, Haasen C, Philipp T, Pietruck F, Franke GH. The impact of living-related kidney transplantation on the donor's life. Transplantation. 2006;81:1268-73.

45. Bullinger M, Kirchberger I, Ware J. Der deutsche SF-36 Health Survey. Übersetzung und psychometrische Testung eines krankheitsübergreifenden Instruments zur Erfassung der gesundheitsbezogenen Lebensqualität. Zeitschrift für Gesundheitswissenschaften. 1995;3:21-36.

46. Bullinger M, Kirchberger I: SF-36. Fragebogen zum Gesundheitszustand Göttingen: Hogrefe; 1998.

47. Smets EM, Garssen B, Bonke B: Manual; Multidimensional Fatigue Inventory Amsterdam: Medical Psychology, Academic Medical Centre; 1995.

48. Smets EM, Garssen B, Bonke B, De Haes JC. The multidimensional fatigue inventory (MFI) psychometric qualities of an instrument to assess fatigue. J Psychosom Res. 1995;39:315-25.

49. Cohen S, Kamarck T, Mermelstein R. A global measure of perceived stress. J Health Human Behav. 1983;24:385-96.

50. Löwe B, Spitzer RL, Zipfel S, Herzog W. Gesundheitsfragebogen für Patienten (PHQ D). Komplettversion und Kurzform. Testmappe mit Manual, Fragebögen, Schablonen. Pfizer: Karlsruhe; 2002.

51. Loch N, Hiller W, Witthöft M. Der Cognitive Emotion Regulation Questionnaire (CERQ). Erste teststatistische Überprüfung einer deutschen Adaption. Z Klin Psychol Psychother. 2011;40:94-106.

52. Garnefski N, Kraaij V, Spinhoven P. Negative life events, cognitive emotion regulation and depression. Pers Individ Dif. 2001;30:1311-27.

\section{Submit your next manuscript to BioMed Central and we will help you at every step:}

- We accept pre-submission inquiries

- Our selector tool helps you to find the most relevant journal

- We provide round the clock customer support

- Convenient online submission

- Thorough peer review

- Inclusion in PubMed and all major indexing services

- Maximum visibility for your research

Submit your manuscript at www.biomedcentral.com/submit
C Biomed Central 